\title{
The impact of interconnectors on the GB electricity sector and European carbon emissions
}

\author{
Callum MacIver*, Waqquas Bukhsh, Keith Bell \\ University of Strathclyde \\ *Corresponding author: callum.maciver@strath.ac.uk
}

\begin{tabular}{l} 
ARTICLE INFO \\
\hline Article history: \\
\hline Keywords: \\
Interconnectors \\
Carbon emissions \\
Electricity markets
\end{tabular}

Carbon emissions
Electricity markets

\begin{abstract}
A model of the European electricity system is used to analyse the impact of increasing interconnection levels between Great Britain and its European neighbours. Scenarios are assessed for 2020, 2025 and 2030. Several policy questions are highlighted around the assessment criteria for approving interconnector projects and the viability of existing investment and remuneration models. Results show that a GB specific carbon tax in 2020 contributes to a relatively high cost of energy and therefore high imports into GB. Increasing GB interconnection capacity in 2020 from $5 \mathrm{GW}$ to $8.4 \mathrm{GW}$ facilitates additional imports and brings down the annual cost of electricity for GB consumers by $€ 639 \mathrm{~m}$. Analysis for 2025 and 2030 shows that additional interconnectors, the removal of the additional GB carbon tax and changes to the generation background lead to GB experiencing increased interconnector exports and reduced interconnector utilisation. This lessens or reverses the impact of new GB interconnection on GB consumer prices. It also leads to a significant reduction in revenue potential for future interconnectors. Carbon emission analysis indicates that inconsistencies in carbon pricing across different countries, like the extra GB price support, can lead to perverse outcomes with reduced GB emissions but increased total European emissions.
\end{abstract}

\section{Introduction}

In recent years there have been growing moves to address the global consensus that nations should act to reduce their dependence on heavily polluting fossil fuels for servicing their energy needs. To date, Europe and the electricity sector in particular have been at the forefront of this global push. Together, wind and solar energy now meet over 15\% of electrical demand across Europe with further plans to expand this significantly in the coming years as well as a drive to enhance cross border integration of electricity markets (EurObserv'ER, 2019; European Comission, 2014b). Great Britain (GB) has contributed significantly to the rapid rise in renewable generation with wind and solar now accounting for over $30 \%$ of national installed generation capacity (National Grid ESO, 2020). Further significant plans for expansion of renewables are in place, especially in the offshore wind sector with a government supported target for $30 \mathrm{GW}$ of installed capacity by 2030 (HM Government, 2019) recently being superseded by a policy commitment from government of $40 \mathrm{GW}$.

In order to facilitate such a rapid expansion in renewables and support general aims of delivering security of supply and carbon emission reduction there has also been a significant drive in place to expand the level of interconnection between countries in Europe. In the context of the European Union, an interconnector is defined as "a transmission line which crosses or spans a border between member states and which connects the national transmission systems of the member states" (European Parliament, 2009). There are specific European 
Commission targets to increase interconnection capacity between member states to $10 \%{ }^{1}$ by 2020 and $15 \%$ by 2030 which form part of a wider plan for increased energy union (European Comission, 2014a). In GB the cap \& floor regulatory regime, a hybrid between the merchant investment route previously preferred in the $\mathrm{UK}^{2}$ and the regulated asset approach more commonly applied on mainland Europe has recently been implemented by the regulator Ofgem to incentivise greater build out of interconnection capacity (ofgem, 2013).

Given its isolated geographical position, GB has historically had a low level of interconnection with its European neighbours with the only option for facilitating cross border electricity flows being high capital expenditure, high voltage direct current (HVDC) subsea cable solutions. The recent completion of the $1 \mathrm{GW}$ NEMO project connecting GB with Belgium brought total GB interconnection capacity to nearly $5 \mathrm{GW}$ ( $2 \mathrm{GW}$ to France, $1 \mathrm{GW}$ to Netherlands, $500 \mathrm{MW}$ to Republic of Ireland and $450 \mathrm{MW}$ to Northern Ireland), a ratio of about $5 \%$ compared with installed generation capacity.

Several other projects have also been granted provisional licences under the cap \& floor scheme while a small number of projects continue to pursue the merchant exemption route. This means there is a large pipeline of future GB interconnector projects with four projects totalling $5 \mathrm{GW}$ currently under active development with many more in planning, at least five of which are projects with credible advanced plans which could potentially see GB interconnector capacity more than treble within the next 5-10 years (National Grid Interconnectors, 2018).

Given this dramatic change in the make-up of the electricity sector and the increasing reliance on crossborder trades it is important to be able to model what role interconnectors can be expected to play in the GB system in terms of how they are utilised and the expected direction of flows as the system background evolves. Interconnectors reduce prices in importing markets by providing increased competition for more expensive generators whereas they increase prices in exporting markets by providing greater access to demand for more expensive generators which would otherwise be priced out of the domestic market (Turvey, 2006).

In addition, it is important to understand the impact these changes will have on other key electricity industry stakeholders as it can be expected that impacts will be felt across the spectrum. Consumers will be impacted by changes to electricity prices, producers impacted by changes in market access \& utilisation and governments by how interconnectors interact with key policy aims such as maintaining security of supply and facilitating carbon reduction.

This paper describes a representative market model of the European electricity system and uses it to analyse how developments in generation, price and interconnection backgrounds could impact key metrics over the course of the next decade with a focus on GB but with consideration to wider European impacts on issues like carbon emissions. Section 2 gives a full explanation of the model and the assumptions which underpin the impact quantification framework. Section 3 discusses the methodology used to develop the various generation background, price and interconnector scenarios which allow for detailed examination of their future impact on the electricity sector. Section 4 presents and discusses the model outputs focusing on the impact of the various future scenarios on electricity prices, interconnector flows and carbon emission while Section 5 details the policy lessons that can be drawn around the impact of interconnectors on the GB generation fleet and carbon emissions as well the efficacy of the GB carbon price floor policy instrument.

\section{Model Development}

\subsection{Problem Background}

Fundamental to the challenge of modelling interconnector flows is generating a reliable representation of the price differences between connecting markets. The work described in this paper models the kind of unit commitment processes used by market participants to dispatch their generation to meet time series of demand,

\footnotetext{
${ }^{1}$ This is defined as the ratio of interconnection capacity to installed generation capacity.

${ }^{2}$ Merchant interconnection projects in the EU require special exemption from the main regulated regime (Dutton, 2016).
} 
subject to technical constraints on the generation plant and available transfer capacities on the network. As is the case in reality, the ultimate market prices flow from a wide range of relevant model input parameters. Each of these are described in greater detail in the remainder of this section. Similar system level modelling approaches have been utilised in other academic literature previously (Deane et al., 2015; Houghton et al., 2012). Similarly, in the mid part of the previous decade, a number of reports from consultancies addressing similar issues around the impacts of interconnection on the GB system were made public, often commissioned by government (Aurora Energy Research, 2016; Baringa, 2014; Redpoint Energy Limited, 2013). In such cases the detailed assumptions are not always made publicly available and this work seeks to provide a contemporary and updated viewpoint from an academic perspective. The Electricity System Operator (ESO) in GB also uses a similar modelling framework, based on the BID3 modelling tool to feed analysis of future generation patterns and interconnector flows into major reports such as the system operability framework (Bell and Staffell, 2016).

In reality there are a multitude of factors that influence the market price of electricity in a country in any given hour and to how markets interact between countries. Other research has looked at the problem of interconnector flows and market interactions from an economic and markets based perspective. (Geske et al., 2020) and (Newbery et al., 2019) each undertake historical analysis of interconnector flows and market positions to assess the impact of trading inefficiencies under different levels of market coupling. (Ward et al., 2019) provided a recent critique of traditional merit order based market models that rely on short-run marginal costs, as proposed in this paper. The paper argues that such methods have a tendency to underestimate the spread and volatility of prices through a lack of consideration of the true business model for certain types of generation and how that impacts market bid prices.

These studies highlight specific market issues that are not easily factored into the perfect foresight, perfectly coupled modelling framework that is proposed. While acknowledging that there are certain limitations to the accuracy of the modelling that can be undertaken, a validation exercise is undertaken in Section 4.1 that shows the framework does still provide a good replication of a historic year. In addition, the paper proposes a scenario based methodology, outlined in Section 3. In total, 56 distinct scenarios are assessed in the paper with varying generation backgrounds, price scenarios and interconnector scenarios. This allows key trends to be assessed and meaningful insights to be made on the influence of differing future input scenarios on key power system metrics like relative market prices, interconnector flow patterns, generator utilisation and carbon emissions.

\subsection{Model Overview}

A European scale transmission system model has been developed that models the behaviour of a coupled European electricity market. The model has been built using ANTARES, an open source electricity market modelling tool developed by French system operator RTE (M Doquet et al., 2011). Each European country is represented by a single node (with the exception of the UK and Denmark, each with two nodes denoting separate islanded regions) with modelling of an appropriate generation mix separated by type while constraints are imposed on the maximum net transfer capacity (NTC) of electricity trades that can take place between connected countries. The implementation takes the form of a unit commitment (UC) model that determines a schedule of generation units that minimises "the overall system operation cost over a week, taking into account all proportional and non-proportional generation costs, as well as transmission charges and "external" costs such as that of the unsupplied energy (generation shortage) or, conversely, that of the spilled energy (generation excess)" (RTE, 2019a). It is constrained by the minimum and maximum production of each generation type, the maximum rate of change of production from each generator and the minimum amount of time for which it must be on if committed to run or run if it is not needed.

In this study, each year is modelled as a sequence of hours, coupled by time-related constraints such as generation ramp rates. The model is capable of representing the operation of storage facilities such as pumped hydro power. The model is solved in weekly blocks, which are coupled for the whole year with constraints respecting hydro-reservoir storage capacities (see section 2.4). Transmission system flows are driven by price differences between the modelled nodes assuming a perfectly coupled market with within-week foresight. Renewable generation availability is modelled across Europe with reference to real historical outputs which respect temporal and spatial correlations.

The future dispatch of generation and the power flows and wholesale market prices consequential to it are 
of course, heavily dependent on the background of installed generation capacity, its type and its location, as well as demand. These, in turn, are dependent on not just on government policies but also the state of the wholesale energy market, capacity markets, network capacity, generation technology, fuel prices, local planning constraints and the responses of existing generation owners and new investors to all these influences. Future generation backgrounds are therefore highly uncertain.

The goal in this work has been to use a credible view from a recognised authority that can allow a reasonable exploration of the likely impacts of different levels of interconnection between GB and other countries. The European Network of Transmission System Operators for Electricity (ENTSO-E) and its gas equivalent, ENTSOG, are formed of national TSOs from across the continent and were formally established by the EU with responsibilities, among other things, to produce scenarios (European Parliament, 2009) . Every 2 years, they are obliged to develop and publish a set of system scenarios and an associated Ten Year Network Development Plan (TYNDP). The most recent edition available at the start of the work described here was that published in 2018. As the 2018 TYNDP Scenario report noted, "The scenarios in the TYNDP 2018 have been built as realistic and technically sound, based on forward looking policies, whilst also being ambitious in nature and aiming at reducing emissions by 80 to $95 \%$ in line with EU targets for 2050 . They will be used by ENTSOs and other organisations to analyse the future of the European energy system". Further, "Dozens of representatives from all sides of the energy sector, consumer and environmental associations, governments" were involved in the construction of the scenarios. The published detail includes the full set of inputs required for undertaking studies like that described here including, for each country in Europe, time series of demand, generation capacity projections and NTCs between each country. As a result, the TYNDP 2018 scenarios for 2020, 2025 and 2030 were adopted as the starting point for the work reported here. (ENTSO-E, 2018a). A geographical representation of the base case model is presented in Figure 1 showing 35 system nodes and their associated transmission connections.

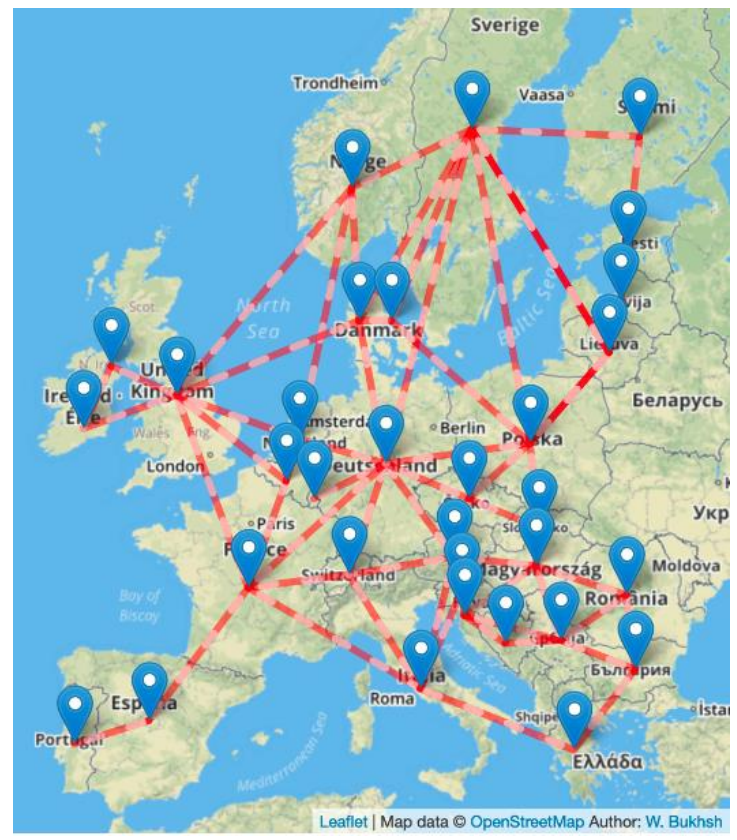

Figure 1 - geographical representation of European electricity market model

\subsection{Thermal generation}

Thermal generation is split by type within each country or node of the model according to the corresponding installed capacity rating given in the ENTSO-E generation background being considered. Standard unit sizes are used for each type of generation such that a representative number of units are defined for each thermal set in each country or node. Other essential operational parameters are defined for each generation type in the model including outage rates, minimum up and down time, minimum stable power as well as financial criteria including start-up costs and market bid price and, finally, representative rates of carbon emissions. With the 
exception of the marginal cost of generation which sets the central market bid price which is defined for each generation type in the model (discussed in section 3.2), the assumptions discussed above remain fixed throughout all the scenarios investigated and are detailed according to generation type in Table 1 using information from ENTSO-E as far as possible (ENTSO-E, 2018b).

Table 1 - Operational parameters assigned by generation type (data taken from ENTSO-e TYNDP).

\begin{tabular}{|c|c|c|c|c|c|c|}
\hline & $\begin{array}{c}\text { Efficiency } \\
(\%)\end{array}$ & $\begin{array}{c}\text { Min } \\
\text { stable } \\
\text { power } \\
(\%)\end{array}$ & $\begin{array}{c}\text { Min up } \\
\text { time } \\
\text { (hrs) }\end{array}$ & $\begin{array}{c}\text { Min } \\
\text { down } \\
\text { time } \\
\text { (hrs) }\end{array}$ & $\begin{array}{l}\text { Start-up } \\
\text { cost }(€ k)\end{array}$ & $\begin{array}{c}\mathrm{CO2} \\
\text { emissions } \\
\text { (tons/MWh) }\end{array}$ \\
\hline Gas - Low & 44 & \multirow{3}{*}{35} & \multirow{3}{*}{4} & \multirow{3}{*}{4} & \multirow{3}{*}{170} & 0.466 \\
\hline Gas - Med & 52 & & & & & 0.395 \\
\hline Gas - High & 58 & & & & & 0.354 \\
\hline CHP & 58 & 30 & 4 & 4 & 170 & 0.354 \\
\hline Coal & 40 & 43 & 6 & 6 & 80 & 0.846 \\
\hline Lignite & 40 & 43 & 8 & 8 & 150 & 0.909 \\
\hline Oil & 35 & 35 & 3 & 3 & 30 & 1.029 \\
\hline Nuclear & 33 & 50 & 12 & 12 & 250 & 0.000 \\
\hline $\begin{array}{c}\text { Other RES / } \\
\text { Biofuels }\end{array}$ & 40 & 35 & 4 & 4 & 80 & 0.121 \\
\hline $\begin{array}{c}\text { Other non } \\
\text { RES }\end{array}$ & 35 & 35 & 4 & 4 & 30 & 1.029 \\
\hline
\end{tabular}

Although it is possible to cluster generation by type to simplify the modelling process, for gas plants a greater degree of accuracy is required as there is a clear distinction in the efficiency and therefore relative marginal cost of different plants across the gas fleet, depending on date of construction and other factors. Therefore, to more accurately represent the gas fleet in the model, especially within GB, gas generation is split into three distinct efficiency bands. The proportions of low medium and high efficiency gas represented at each node were defined in discussion with industry experts and with reference to the stated efficiency ratings for the fleet of GB gas plants as shown in Table 2.

Table 2 - Proportion of low, medium and high efficiency plants within the gas generation fleet present in each applicable node of model

\begin{tabular}{|c|c|c|c|}
\hline & Great Britain & $\begin{array}{c}\text { R. Ireland \& } \\
\text { N. Ireland }\end{array}$ & $\begin{array}{c}\text { Rest of } \\
\text { Europe }\end{array}$ \\
\hline Gas - Low & $10 \%$ & $33 \%$ & $0 \%$ \\
\hline Gas - Med & $40 \%$ & $33 \%$ & $50 \%$ \\
\hline Gas - High & $50 \%$ & $33 \%$ & $50 \%$ \\
\hline
\end{tabular}

\subsection{Hydro Generation}

Within ANTARES hydro generation is separated into three distinct categories relating to run-of-river hydro, reservoir storage hydro and pumped storage hydro which are each treated differently. Run-of-river and reservoir storage hydro are linked within the model whereby an expected level of monthly hydro generation is specified along with a percentage split between the two types. In each month, production from the total hydro generation capacity that is assigned to run-of-river is assumed to be evenly distributed across each hour of the month. A heuristic weekly optimisation method is available within ANTARES to optimise the time of utilisation of the remaining hydro generation capacity that is assigned to reservoir storage hydro (RTE, 2019b). The annual energy production expectations used for hydro data in each country are based on 18 years of historical output data given in (Agora Energiewende and Sandbag, 2019) whereas the monthly breakdown in volume and the split between run-of-river and reservoir hydro is derived from 4 years' worth of detailed historical data from the ENTSO-E transparency platform (ENTSO-E, 2020). A representation of pumped storage is included in the model such that the model can chose to make use of temporal arbitrage subject to a daily cycle of charging and discharging with $72 \%$ efficiency (Newbery, 2016). 


\subsection{Wind and Solar Generation}

Wind and solar generation are dispatched as pre-defined time-series for each node within the model. The time-series used are based on historical country by country output data synthesised in Renewable Ninja (Staffell and Pfenninger, 2016). This gives an expected hour by hour country level output in percentage terms that is then scaled to the generation capacity of wind and solar for each country within the generation background scenario being considered. With the aim of preserving the cross-correlations that would have been present between weather and demand profiles, a single historical year of data is chosen and is matched with the historical demand year for which the demand projections for a particular scenario are derived. Wind and solar have no market bid in the model and are assumed to run at their stated output unless curtailed at a set system cost of 50 $€ / M W h$. In this case their presence lowers the marginal system cost via the merit order effect in which more expensive generation is pushed out of the market, as outlined in (Cludius et al., 2014; Hirth, 2018).

\subsection{Demand}

Demand profiles are taken from ENTSO-E projections for 'average year' profiles scaled to the expected total demand associated with each considered future year (ENTSO-E, 2018c).

\subsection{Transmission Connections}

The transmission system connecting nodes in the model is represented by single transmission links for which net transfer capacities (NTCs) are defined. An NTC can be defined independently for each direction with a time series of values specific to each hour. However, here, the NTCs are assumed to have a flat annual profile set to the value of the expected transmission capacity for the given year of operation based on ENTSO-E projections (ENTSO-E, 2018b). This is a simplification which neglects the fact that, in reality, NTCs, especially for AC connections, vary according to generation patterns and the presence of maintenance outages on the network, both on the interconnection border and within the network on each side.

\subsection{Losses}

The effect of onshore transmission losses is included in the modelling via a fixed $2 \%$ increase in the demand within each country such that additional generation is required to meet typical onshore system losses. In addition, a financial hurdle cost of $€ 1 / \mathrm{MWh}$ is applied to land based cross border flows in the model so that a trade is only made if the benefit of the trade exceeds the approximate cost of losses to accommodate it.

In contrast to much of the rest of Europe the island of Great Britain is interconnected to its neighbours solely via HVDC transmission links. Given the large distances involved and the associated line and converter losses it is appropriate to explicitly model losses on these links. These are modelled as a fixed percentage of the power exchange such that the exporting country has to generate additional power to cover the losses associated with the HVDC link and allow for the full capacity of the transmission link to be realised at the importing end. There are no additional hurdle costs applied to these links but the inclusion of the real loss figure creates a financial hurdle to flows over the links such that the value of the interconnector flow, given as the product of the price difference between the markets and the magnitude of the flow, must be greater than the cost of the additional power that needs to be generated to cover the losses. In scenarios where there are expected to be multiple HVDC links between GB and one of its neighbours, a weighted average loss figure is applied based on known or expected loss figures for each link. The losses applied to each link are outlined later in Table 6.

\section{Methodology and Scenario Development}

To investigate how interconnectors and the changing generation mix across Europe may impact the GB electricity sector in the coming years a number of credible scenarios have been developed covering the years 2025 and 2030 with different generation backgrounds and GB interconnector pathways. In addition, in order to provide a basis for comparison, a 2020 case has been modelled to show how the system would have been expected to operate without the societal 'lockdown' brought in by various governments to manage the spread of the SARS-CoV-2 virus associated with the COVID-19 disease. 


\subsection{Generation Background Scenarios}

This work examines the impact of five distinct ENTSO-E derived background scenarios covering three separate time horizons. This consists of single best estimate (BE) background cases for 2020 and 2025 and three different pathway scenarios for 2030 termed as sustainable transition (2030 ST), European Commission scenario (2030 EUCO) and distributed generation (2030 DG) as highlighted in Figure 2 and Table 3.

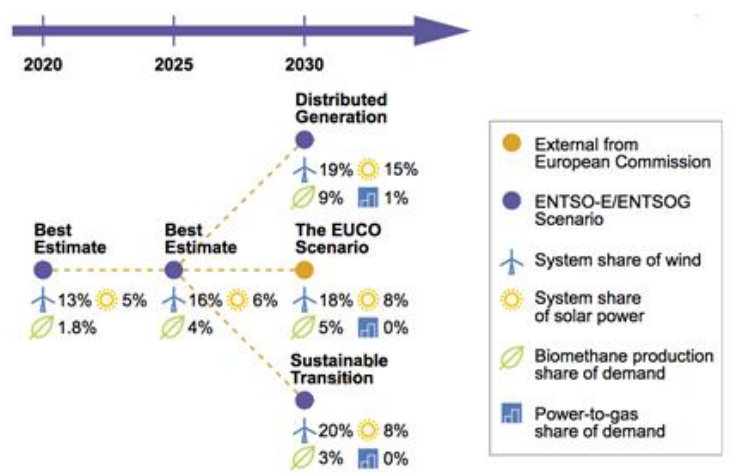

Figure 2 - Background Generation \& Demand Scenarios. adapted from (ENTSO-E, 2018a)

Table 3 - Summary of generation capacity in each background scenario (GW)

\begin{tabular}{|c|c|c|c|c|c|}
\hline Scenario & 2020 BE & 2025 BE & $\begin{array}{c}\mathbf{2 0 3 0} \\
\text { EUCO }\end{array}$ & 2030 DG & 2030 ST \\
\hline Gas/CHP & 209.7 & 214.9 & 194.7 & 209.1 & 221.0 \\
\hline Hard coal & 75.8 & 58.1 & 61.7 & 38.8 & 45.6 \\
\hline Hydro & 256.9 & 275.4 & 293.0 & 291.5 & 291.5 \\
\hline Lignite & 49.9 & 44.3 & 45.5 & 40.8 & 41.2 \\
\hline Nuclear & 120.7 & 94.6 & 111.1 & 83.3 & 83.3 \\
\hline Oil & 12.7 & 9.6 & 24.2 & 15.0 & 8.3 \\
\hline Other non-RES & 18.4 & 18.8 & 1.9 & 17.4 & 17.4 \\
\hline $\begin{array}{c}\text { Other RES/ } \\
\text { Biofuels }\end{array}$ & 40.1 & 43.5 & 59.9 & 47.1 & 47.3 \\
\hline Solar-PV & 134.4 & 182.9 & 238.8 & 419.6 & 245.2 \\
\hline Wind & 199.1 & 252.4 & 295.9 & 302.9 & 303.1 \\
\hline
\end{tabular}

\subsection{Price Scenarios}

Each of the background scenarios in the model is coupled with a set of price assumptions which ultimately lead to the creation of hourly market bid prices for each generation type within the scenario and so drive the system flows and final results. The main differences between price scenarios relate to how carbon emissions are priced. The EU emissions trading scheme (EU-ETS) sets the carbon price across the continent and is one important element alongside assumptions on fuel price and operational costs which set the marginal price and therefore market bid of different generation types. The final market bid prices which are derived from the price input assumptions are presented in Table 4 alongside the corresponding EU-ETS carbon price. For the single 2025 background scenario, two distinct price scenarios are examined based on assumed differences in the EUETS carbon price and the underlying fuel costs while each of the other background scenarios has their own distinct input prices which closely follow assumptions given as part of the TYNDP (ENTSO-E, 2018b). The two 2025 scenarios are distinguished as one on which coal comes before gas in the generation 'merit order' (2025 C-b-G) and the other has gas before coal (2025 G-b-C). The former retains a relatively business as usual carbon price which, together with the assumption on the relative prices of coal and gas, makes electricity generated from coal cheaper than that from gas. The latter has such a high carbon price that gas comes 'in merit' before coal does. 
Table 4 - Base case market bid scenarios by generation type with associated carbon price (€/MWh unless stated)

\begin{tabular}{|c|c|c|c|c|c|c|}
\hline \multirow{2}{*}{ Type } & \multicolumn{7}{|c|}{ Price Scenario } \\
\cline { 2 - 7 } & $\begin{array}{c}\mathbf{2 0 2 0} \\
\text { BE }\end{array}$ & $\begin{array}{c}\mathbf{2 0 2 5} \\
\text { C-b-G }\end{array}$ & $\begin{array}{c}\mathbf{2 0 2 5} \\
\text { G-b-C }\end{array}$ & $\begin{array}{c}\mathbf{2 0 3 0} \\
\text { EUCO }\end{array}$ & $\begin{array}{c}\mathbf{2 0 3 0} \\
\text { DG }\end{array}$ & $\begin{array}{c}\mathbf{2 0 3 0} \\
\text { ST }\end{array}$ \\
\hline Gas Low & 70.53 & 81.04 & 95.04 & 80.23 & 105.1 & 121.42 \\
\hline Gas Med & 59.93 & 68.82 & 80.66 & 68.13 & 89.18 & 102.99 \\
\hline Gas High & 53.89 & 61.87 & 72.48 & 61.25 & 80.12 & 92.5 \\
\hline Coal & 51.9 & 57.93 & 83.31 & 73.68 & 79.35 & 108.96 \\
\hline Lignite & 42.22 & 48.57 & 75.84 & 57.57 & 66.75 & 98.56 \\
\hline Nuclear & 32.45 & 32.45 & 32.45 & 32.45 & 32.45 & 32.45 \\
\hline Oil & 159.64 & 191.53 & 195.64 & 184.33 & 198.73 & 274.84 \\
\hline CHP & 53.89 & 61.87 & 72.48 & 61.25 & 80.12 & 92.5 \\
\hline Other non-RES & 60.39 & 67.59 & 98.44 & 85.59 & 93.3 & 129.3 \\
\hline $\begin{array}{c}\text { Other RES / } \\
\text { Biofuels }\end{array}$ & 38.77 & 42.49 & 42.49 & 46.6 & 46.6 & 55.6 \\
\hline \hline $\begin{array}{c}\text { EU-ETS } \\
\text { carbon price } \\
(\boldsymbol{E} / \text { tonne) }\end{array}$ & 25 & 30 & 60 & 30 & 50 & 85 \\
\hline
\end{tabular}

In addition to the European wide carbon price, in Great Britain at the time of writing there is an additional levy on polluters of $£ 18 / \mathrm{tCO}_{2} \mathrm{e}$ (assumed to convert to $€ 21 / \mathrm{tCO}_{2} \mathrm{e}$ ) via the carbon price floor (Hurst, 2018). This additional cost was part of a UK specific drive to reduce fossil fuel generation and was also partly in response to historically low prices in the EU-ETS of around $€ 5 / \mathrm{tCO}^{2} \mathrm{e}$ which have only recently picked up in value by a factor of around four. Discussion with industry bodies suggests that the GB specific carbon price floor will likely be removed in line with the phase out of coal plants in GB around the middle of the next decade. Although this levy is taken absent from the set of generation costs in the two main 2025 scenarios, it should be included in market bid prices for generation in GB in the 2020 scenario. However, to assess the impact of the carbon price floor still being present in GB in 2025, a further two scenarios are considered: 2025 C-b-G GB levy and 2025 G-b-C GB levy. This means that, in total, four 2025 price scenarios are examined in addition to the single 2020 scenario and three for 2030. Table 5 outlines the GB specific generation market bid prices which are used in all the scenarios in which the GB carbon price floor is assumed to be retained. All other locations in the model use the market bid values outlined in Table 4 in all cases. GB prices are as in Table 4 for the scenarios in which the GB carbon levy is absent.

Table 5 - GB \& NI market bid price for scenarios which include additional GB carbon levy (€/MWh unless stated)

\begin{tabular}{|l|c|c|c|}
\hline \multirow{2}{*}{ Type } & \multicolumn{3}{c|}{ Price Scenario } \\
\cline { 2 - 4 } & $\mathbf{2 0 2 0} \mathbf{B E}$ & $\begin{array}{c}\mathbf{2 0 2 5} \text { C-b-G } \\
\text { GB levy }\end{array}$ & $\begin{array}{c}\mathbf{2 0 2 5} \text { G-b-C } \\
\text { GB levy }\end{array}$ \\
\hline Gas Low & 80.32 & 90.84 & 104.83 \\
\hline Gas Med & 68.21 & 77.11 & 88.95 \\
\hline Gas High & 61.32 & 69.3 & 79.91 \\
\hline Coal & 69.67 & 75.7 & 101.08 \\
\hline Lignite & 61.31 & 67.66 & 94.93 \\
\hline Nuclear & 32.45 & 32.45 & 32.45 \\
\hline Oil & 181.24 & 213.13 & 217.24 \\
\hline CHP & 61.32 & 69.3 & 79.91 \\
\hline Other non-RES & 81.99 & 89.19 & 120.04 \\
\hline Other RES / Biofuels & 38.77 & 42.49 & 42.49 \\
\hline \hline $\begin{array}{l}\text { EU-ETS carbon price }+ \\
\text { GB carbon levy (€/tonne) }\end{array}$ & 46 & 51 & 81 \\
\hline
\end{tabular}

The market price bids are used as centre estimates in the model but moderate daily and seasonal variations are also applied. $\mathrm{A} \pm 5 \%$ winter summer variation on the central market bid prices is applied linearly across the 
year such that in general market prices are higher in winter than in summer to give some reflection of the influence of demand on prices. In addition, a random daily variation is applied with maximum bounds of $\pm 2 \%$ on the central price such that each generation type within each country has a slightly differentiated price on any given day whilst the overall merit order remains generally intact. This aids realism by giving some reflection of the fact that price differences between different types of generation and between different countries are not fixed but vary dynamically in time. Finally, for the most expensive generator in each system, the market bid is set at $10 \%$ above the marginal cost level, reflecting to some degree the phenomenon of scarcity pricing as outlined in (Ward et al., 2019). Further work is required to fully account for this phenomenon in future iterations of the modelling framework.

It should be noted that this work does not attempt to ensure cost recovery of all generation in the mix. This is a complex problem that depends not only on the market value of electricity but on the need for, and opportunity to participate in, future balancing and ancillary service markets. Assessing this is beyond the scope of the current project and the single modelling framework that is deployed. Instead, an assumption is made that the projected future operating capacity is justified via a combination of wholesale and ancillary service revenue streams.

\subsection{GB Interconnection Scenarios}

For each of the eight distinct price scenarios relating to the five generation backgrounds outlined above, a number of credible interconnector scenarios are investigated in which the number of HVDC interconnectors in service between GB and its neighbours is varied. Ten new interconnectors are considered for which the developers' stated commissioning years are shown in Table 6. At the time of writing, Eleclink, IFA2, NSL are all under construction. Seven further interconnectors are considered, each of which a range of industry parties consulted by the authors regards as credible though not guaranteed to be fully developed and with some uncertainty around the commissioning date. For 2020, because 2021 has not been modelled, the effects of each combination of Eleclink, IFA2, NSL or none them is assessed. The credible range of 2025 and 2030 interconnection scenarios were determined through discussions with industry experts taking into account best estimates of possible connection dates. The full set of GB interconnector scenarios is outlined in Table 7.

It should be noted that two $1.4 \mathrm{GW}$ links to France are currently at some stage of development with a planned commissioning date of 2023 or later. For interconnector scenarios 4, 6 and 7 in 2025 only one of these links is assumed to be in-service. The modelling uses the average of anticipated losses on these two links and the results are assumed to be representative of either of them being in service. For each study year, one scenario that is deemed to be the central or best estimate is highlighted in green in Table 7. Finally, Scenario 0, is an additional 2018 scenario and is highlighted blue, denoting that it will only be used in the validation of the model, section 4.1 , and not in the main body of results. 
Table 6 - Existing and planned GB interconnectors considered

\begin{tabular}{|l|c|c|c|c|}
\hline \multicolumn{1}{|c|}{ Name } & $\begin{array}{c}\text { Connected } \\
\text { Market }\end{array}$ & $\begin{array}{c}\text { Assumed } \\
\text { Losses }\end{array}$ & $\begin{array}{c}\text { Capacity } \\
\text { (MW) }\end{array}$ & $\begin{array}{c}\text { Commission } \\
\text { Year (real, } \\
\text { expected or } \\
\text { estimated) }\end{array}$ \\
\hline IFA & France & $2.34 \%$ & 2000 & 1986 \\
\hline Moyle & N. Ireland & $2.36 \%$ & 500 & 2002 \\
\hline BritNed & Netherlands & $3.00 \%$ & 1000 & 2011 \\
\hline EWIC & Rep. of Ireland & $4.68 \%$ & 500 & 2012 \\
\hline NEMO & Belgium & $2.60 \%$ & 1000 & 2019 \\
\hline Eleclink & France & $2.50 \%$ & 1000 & 2020 \\
\hline IFA2 & France & $3.03 \%$ & 1000 & 2020 \\
\hline NSL & Norway & $4.92 \%$ & 1400 & 2021 \\
\hline Greenlink & Rep. of Ireland & $2.64 \%$ & 500 & 2023 or later \\
\hline FAB Link & France & $2.88 \%$ & 1400 & 2023 or later \\
\hline Viking Link & Denmark & $5.04 \%$ & 1400 & 2023 or later \\
\hline GridLink & France & $2.62 \%$ & 1400 & 2023 or later \\
\hline NorthConnect & Norway & $4.62 \%$ & 1400 & 2026 or later \\
\hline NeuConnect & Germany & $4.80 \%$ & 1400 & 2026 or later \\
\hline Aquind & France & $3.04 \%$ & 2000 & 2026 or later \\
\hline
\end{tabular}

Table 7 - GB interconnection scenarios considered for each study year. Best estimate scenario for each study year is highlighted in green.

\begin{tabular}{|c|c|c|c|}
\hline $\begin{array}{c}\text { Scenario } \\
\text { No. }\end{array}$ & $\begin{array}{l}\text { Study } \\
\text { Year }\end{array}$ & GB Interconnection Scenario & $\begin{array}{c}\text { Total GB } \\
\text { Interconnection } \\
(\mathrm{GW})\end{array}$ \\
\hline $\mathbf{0}$ & 2018 & Existing minus NEMO & 4 \\
\hline 1 & \multirow{5}{*}{2020} & Existing & 5 \\
\hline 2 & & Existing, Eleclink & 6 \\
\hline 3 & & Existing, Eleclink, IFA2 & 7 \\
\hline 4 & & Existing, Eleclink, NSL & 7.4 \\
\hline 5 & & Existing, Eleclink, IFA2, NSL & 8.4 \\
\hline 1 & \multirow{8}{*}{2025} & 2020 all & 8.4 \\
\hline 2 & & 2020 all, Greenlink & 8.9 \\
\hline 3 & & 2020 all, Viking Link & 9.8 \\
\hline 4 & & 2020 all, FAB Link (or GridLink) & 9.8 \\
\hline 5 & & 2020 all, Viking Link, Greenlink & 10.3 \\
\hline 6 & & $\begin{array}{l}2020 \text { all, Viking Link, FAB Link } \\
\text { (or GridLink) }\end{array}$ & 11.2 \\
\hline 7 & & $\begin{array}{l}2020 \text { all, Viking Link, Greenlink, FAB Link } \\
\text { (or GridLink) }\end{array}$ & 11.7 \\
\hline 8 & & $\begin{array}{l}2020 \text { all, Greenlink, Viking Link, FAB Link, } \\
\text { GridLink }\end{array}$ & 13.1 \\
\hline 1 & \multirow{6}{*}{2030} & 2025 all & 13.1 \\
\hline 2 & & 2025 all, NorthConnect & 14.5 \\
\hline 3 & & 2025 all, NeuConnect & 14.5 \\
\hline 4 & & 2025 all, Aquind & 15.1 \\
\hline 5 & & 2025 all, NorthConnect, NeuConnect & 15.9 \\
\hline 6 & & 2025 all, NorthConnect, NeuConnect, Aquind & 17.9 \\
\hline
\end{tabular}




\section{Results and Discussion}

For each of the different scenarios outlined in Section 3, ANTARES was used to simulate a full year of European electricity system operation, the key results of which are presented and discussed in the remainder of Section 4.

\subsection{Comparison with Observed Data}

To give confidence that the model is producing sensible results a back-cast can be performed for a chosen year. A full back-cast would require the compilation and validation of detailed country level input data including generator, capacity, efficiencies and availability, fuel prices, hourly NTCs, demand and renewable energy output. Much of this information is nominally available via the ENTSO-E transparency platform (ENTSO-E, 2020), however there is often incomplete data when looking across all countries represented in the model and validation of this data against other national data sources does not always yield a strong match. In light of these limitations, a partial back-cast has been performed for 2018 using Scenario O. This Scenario assumes that the 2020 generation capacity and interconnection background scenario, outlined in the previous section, is sufficiently close to 2018 conditions to be used as an approximation. However, realised 2018 data for demand and renewable energy in each country are included in the scenario based on ENTSOE outturn data. In addition, 2018 coal and gas future trading prices have been obtained (Investing.com, 2020) and averaged to a quarterly price, along with the real EU-ETS carbon prices, averaged to a monthly price. It is assumed that the fuel prices can act as a proxy for prices faced across all countries and using the same methods as outlined in Table 4, a set of market bid prices for different generation types in each country is developed that varies across the year in a manner that should be broadly representative of real 2018 costs. Finally, real outages on each of the GB interconnectors are included. The focus of this investigation is not to produce a perfect replication of 2018 but to assess whether with a sensible set of input parameters, the model is able to generate a set of realistic outputs and capture the key elements of system behaviour.

Table 8 shows the breakdown of generation and consumption for EU28 nations (so still including the UK, despite recent departure from the EU) for 2018 as reported in (Agora Energiewende and Sandbag, 2019) compared with the aggregated output of the model for the 2018 scenario for the same EU28 nations. It should be noted that there may be some deviations in how generation is categorised between the model input data and the observed output and that some countries within the model which are not part of the EU28 (e.g. Norway) are not included in this analysis.

Table 8 - Comparison between aggregated 2020 model outputs and 2018 observed data for EU28 nations

\begin{tabular}{|c|c|c|c|c|c|c|}
\hline & \multicolumn{2}{|c|}{$\begin{array}{c}\text { 2018 observed } \\
\text { EU28 data }\end{array}$} & \multicolumn{2}{c|}{$\begin{array}{c}\text { 2020 model } \\
\text { EU28 output }\end{array}$} & \multicolumn{2}{c|}{$\begin{array}{c}\text { 2020 model } \\
\text { output vs 2018 } \\
\text { observed data }\end{array}$} \\
\cline { 2 - 7 } & TWh & $\begin{array}{c}\% \text { of } \\
\text { Prod }\end{array}$ & TWh & $\begin{array}{c}\% \text { of } \\
\text { Prod }\end{array}$ & TWh & $\%$ change \\
\hline Lignite & 300 & $9 \%$ & 295 & $10 \%$ & -5 & $-2 \%$ \\
\hline Hard Coal & 319 & $10 \%$ & 189 & $6 \%$ & -129 & $-41 \%$ \\
\hline $\begin{array}{c}\text { Other fossil / } \\
\text { Biomass }\end{array}$ & 321 & $10 \%$ & 285 & $9 \%$ & -36 & $-11 \%$ \\
\hline Gas & 625 & $19 \%$ & 606 & $20 \%$ & -19 & $-3 \%$ \\
\hline Nuclear & 827 & $25 \%$ & 872 & $28 \%$ & 45 & $5 \%$ \\
\hline Hydro & 369 & $11 \%$ & 345 & $11 \%$ & -24 & $-7 \%$ \\
\hline Solar & 127 & $4 \%$ & 111 & $4 \%$ & -16 & $-13 \%$ \\
\hline Wind & 378 & $12 \%$ & 361 & $12 \%$ & -17 & $-4 \%$ \\
\hline Imports & 27 & - & 26 & - & -1 & $-4 \%$ \\
\hline Consumption & 3294 & - & 3090 & - & -204 & $-6 \%$ \\
\hline Production & 3266 & - & 3064 & - & -202 & $-6 \%$ \\
\hline
\end{tabular}

In general terms it can be seen that the model gives very similar outcomes in terms of overall generation and consumption patterns. Within the model, the total consumption and production values based on the ENTSO-E 
scenario input data are found to be around $6 \%$ lower than the figures in the 2018 observed data. In addition to this, wind and solar output is modelled to be around 4\% and 13\% lower than the 2018 observed data. Each of these speak to a potential underestimate in the ENTSO-E outturn data. It can be seen that the model gives a close approximation to the total observed share of production for gas, lignite, biomass and other thermal plants. It seems that the model slightly overestimates nuclear output compared with 2018 but the only fuel type which shows a significant deviation is coal output which is around $40 \%$ lower in the 2018 model vs the 2018 data. This suggests that coal is perhaps slightly overpriced relative to gas for a portion of the year in some locations. Other factors which will contribute to differences between modelled and observed results are the fact that real system constraints and other market inefficiencies within countries will not be picked up by the simplified single node representation deployed in the model.

In addition to the whole system generation analysis a more detailed examination of GB interconnector flows is also presented in Table 9. It can be seen that the model gives a good representation vs realised GB imports from and exports to each country for 2018. High imports and low exports over the GB links to both France and the Netherlands are observed, in line with the realised data although the idealised model does overestimate utilisation on the links by twelve and thirteen percentage points respectively. The two links to Ireland both show only a small percentage point overestimation for utilisation against outturn performance and the share of imports and exports is broadly correct. Thus, the total net GB import position from the model is $21.87 \mathrm{TWh}$ vs the realised position of 19.2 TWh showing broad agreement.

Table 9 - GB Interconnector transfer comparison for 2018 validation scenario (TWh)

\begin{tabular}{|c|c|c|c|c|c|}
\hline & & Import & Export & $\begin{array}{c}\text { Net GB } \\
\text { transfers } \\
\text { (import+ve) }\end{array}$ & Utilisation \\
\hline \multirow{2}{*}{ GB-FR } & Realised & 13.26 & 0.39 & 12.88 & $78 \%$ \\
\cline { 2 - 6 } & Model & 15.65 & 0.10 & 15.56 & $90 \%$ \\
\hline \multirow{2}{*}{ GB-ND } & Realised & 6.75 & 0.19 & 6.56 & $79 \%$ \\
\cline { 2 - 6 } & Model & 7.45 & 0.63 & 6.82 & $92 \%$ \\
\hline \multirow{2}{*}{ GB-IE } & Realised & 1.26 & 0.77 & 0.49 & $46 \%$ \\
\cline { 2 - 6 } & Model & 1.81 & 0.53 & 1.27 & $53 \%$ \\
\hline \multirow{2}{*}{ GB-NI } & Realised & 0.59 & 1.32 & -0.73 & $48 \%$ \\
\cline { 2 - 6 } & Model & 0.14 & 1.92 & -1.78 & $52 \%$ \\
\hline \multirow{2}{*}{ Total } & Realised & 21.86 & 2.66 & 19.20 & - \\
\cline { 2 - 6 } & Model & 25.05 & 3.18 & 21.87 & - \\
\hline
\end{tabular}

The validation process therefore shows that the model is capable of broadly replicating both the generation merit order across Europe and the relative price differences between GB and neighbouring countries. The latter directly drives the level of interconnector flows which have shown to be representative. This gives confidence that the scenario based methodology, the results of which are presented in the following sections, should give a representative view of the impacts or trends that can be expected under the range of different future generation background, interconnector and price scenarios that are assessed.

\subsection{Market Price Analysis}

\subsubsection{Relative overall price of markets}

One of the key outputs from the model is hourly market price in each country. This parameter ultimately determines the level and direction of interconnector flows in each hour and by looking across the whole year a picture can be gained of the relative cost to the consumer of energy supply at each node in the model, i.e. in each country. In this analysis we focus only on GB and the eight other countries (Northern Ireland (NI), Republic of Ireland (IE), France (FR), Norway (NO), Netherlands (ND), Belgium (BE), Denmark (DK) and Germany (DE)) to which it is already interconnected or might be in the future scenarios examined. Table 10 is used to give a summary of the relative costs of electricity in each of these markets in the eight main generation background and price scenarios. In each case, interconnector capacity between GB and other countries is the 'best estimate' for that year as shown in Table 7. For each simulation, a simple arithmetic average electricity 
price (not weighted by size of demand) across a set of 9 countries is shown: GB plus the countries to which GB might be interconnected. This is the average group price (AGP). Each row of Table 10 then shows the deviation of the average price in each country from the AGP.

It can first be observed that the background generation and price scenarios have a large impact on the average system cost that is observed, as indicated by the AGP value. We see average system costs for the 9 countries rising from around $€ 52.7 / \mathrm{MWh}$ in the 2020 case to around $€ 60 / \mathrm{MWh}$ in the two coal before gas 2025 scenarios and around $€ 75 / \mathrm{MWh}$ for the two 2025 gas before coal scenarios. There is also a large spread in average system costs in the three 2030 scenarios with the 2030 Sustainable Transition scenario reaching an AGP of nearly $€ 95 / \mathrm{MWh}$. These changes are to a large extent driven by the assumptions made regarding the carbon cost applied via the EU-ETS which rises from $25 € /$ tonne in 2020 to $85 € /$ tonne in the 2030 ST scenario. (See Table 4).

Table 10 - Market price deviation from Average Group Price (AGP) for best estimate interconnector scenario within each background scenario

\begin{tabular}{|c|c|c|c|c|c|c|c|c|c|c|}
\hline \multicolumn{2}{|c|}{$\begin{array}{c}\text { Background } \\
\text { scenario \& AGP } \\
(€ / M W h)\end{array}$} & \multicolumn{9}{|c|}{ Market price deviation from group average ( $€ /$ MWh) } \\
\hline & AGP & NI & IE & GB & ND & DE & BE & DK & NO & FR \\
\hline $\begin{array}{l}2020 \text { BE } \\
\text { (S3) }\end{array}$ & 52.7 & 8.1 & 5.1 & 4.6 & -0.8 & -1.8 & -1.9 & -2.7 & -4.1 & -6.5 \\
\hline $\begin{array}{c}2025 \text { C-b-G } \\
\text { (S6) }\end{array}$ & 60.4 & 4.9 & 4.8 & -0.8 & -0.2 & -0.9 & 0.4 & -1.5 & -3.9 & -2.9 \\
\hline $\begin{array}{c}2025 \text { C-b-G } \\
\text { GB levy (S6) }\end{array}$ & 61.5 & 6.2 & 5.6 & 1.2 & -0.9 & -1.7 & -0.1 & -2.0 & -4.7 & -3.6 \\
\hline $\begin{array}{l}2025 \text { G-b-C } \\
\text { (S6) }\end{array}$ & 75.0 & 3.9 & 4.0 & -3.2 & 1.3 & 1.3 & 0.9 & 0.1 & -2.9 & -5.3 \\
\hline $\begin{array}{l}2025 \text { G-b-C } \\
\text { GB levy (S6) } \\
\end{array}$ & 76.5 & 4.9 & 4.5 & -1.0 & 0.5 & 0.3 & 0.3 & -0.5 & -3.1 & -5.8 \\
\hline $\begin{array}{l}2030 \text { EUCO } \\
\text { (S5) }\end{array}$ & 62.5 & 0.9 & 0.9 & -2.8 & 2.5 & 2.2 & 1.9 & 0.9 & -1.9 & -4.6 \\
\hline $\begin{array}{c}2030 \text { DG } \\
\text { (S5) }\end{array}$ & 76.8 & 4.9 & 4.7 & -1.1 & -0.1 & -0.8 & 0.8 & -0.2 & -5.3 & -2.7 \\
\hline $\begin{array}{l}2030 \mathrm{ST} \\
\text { (S5) }\end{array}$ & 94.9 & 1.1 & 1.1 & -2.9 & 1.5 & 1.8 & 1.4 & 1.4 & -1.5 & -3.9 \\
\hline
\end{tabular}

The remainder of Table 10 shows the relative price of each market under each of the 8 background scenarios. For 2020, alongside both Irish markets, GB is found to be one of the more expensive markets (marked red) with an average price in the best estimate interconnector scenario that is $€ 5.0 / \mathrm{MWh}$ higher than the group average of its neighbours in mainland Europe and Scandinavia. Equally, France and Norway are found to be the cheapest markets (marked green). These findings are broadly in line with the recent observed status of the national markets although relative prices do vary over time (European Commision, 2020). In the 2025 coal before gas price scenario with GB carbon costs assumed to be equalised with the rest of Europe, i.e. the GB levy removed, GB shifts from being a high price market to a slightly below average price market with countries like Belgium and the Netherlands now being relatively more expensive on average than GB. This trend is even more pronounced in the 2025 gas before coal scenario which has a high cost of carbon with GB becoming the second cheapest market in the grouping. Adding back in the GB specific carbon floor price can be seen to reverse these trends to some extent. This provides further support to the distorting influence of the carbon price floor outlined in (Newbery et al., 2019).

In each of the 2030 scenarios GB continues its transition to being, on average, one of the cheapest markets among its neighbours. The main drivers for this are suggested to be the relatively high levels of renewable penetration in GB and the local phase out of coal power which, for countries with remaining capacity, becomes increasingly expensive in future scenarios in line with assumed increases in carbon and fuel costs. Another observation to make is that in the future scenarios the spread of annual average market prices between the group of countries in question has reduced which will be influenced by both the equalising of carbon costs but also the general principle that increasing interconnection between markets acts to converge the prices between those markets (Turvey, 2006). 


\subsubsection{Impact of interconnectors on GB market prices}

This section examines the impact of increased interconnection with a specific focus on GB annual average marginal prices. Figure 3 shows the change in GB annual average marginal price as you add additional interconnectors between GB and its neighbours relative to interconnector scenario 1 in each of the study years and background scenarios examined.

The results for 2020 show that the impact of more interconnectors is to significantly reduce the annual average marginal price. The effect of adding $3.4 \mathrm{GW}$ of interconnector capacity is to reduce the annual average marginal price in GB by $€ 1.81 / \mathrm{MWh}$. This translates to an annual consumer saving of $€ 639 \mathrm{~m}$. GB is a relatively expensive market in 2020 and, as will be shown in Section 4.3, is therefore a net importer of electricity.

In 2025, the coal before gas case with a GB carbon levy still in place (making electrical energy in GB relatively expensive) shows a similar trend to that seen in 2020 as more interconnection capacity is added: an additional $4.7 \mathrm{GW}$ reduces the GB marginal price by $€ 0.95 / \mathrm{MWh}$. In the case with gas before coal and a GB levy and the one with coal before gas and no levy, the overall effect of $4.7 \mathrm{GW}$ of additional interconnection on GB prices is minimal. As will be shown in Section 4.3, the impact on market prices is driven by the changing nature of interconnector transfers and in these scenarios it can be observed that increasing levels GB exports lead to increased GB prices in some hours of the year which counteracts the reduced prices during importing hours. In the G-b-C scenario, average GB prices rise quite significantly with an increase in the annual average marginal price of as much as $€ 0.98 / \mathrm{MWh}$ with the addition of links to Denmark and Ireland although adding further links to France reduces this impact to some extent. Section 4.3 will show that this results from GB becoming a net exporting market in this background scenario.

The results also show that the specific region to which GB is interconnecting with additional capacity has a significant bearing on the relative impact on GB prices. For example increasing capacity from $8.4 \mathrm{GW}$ to $9.8 \mathrm{GW}$ via a new connection to France gives a reduction in GB average prices in all four 2025 scenarios whereas doing so via a new connection to Denmark causes an increase in average GB prices in three out four scenarios.

In 2030, an increase in GB interconnection capacity from 13.1 GW to $17.9 \mathrm{GW}$ (an addition of $4.8 \mathrm{GW}$ ) has the effect of increasing GB average prices in all three scenarios. This results from relatively low GB marginal prices compared with neighbouring countries, as evidenced by Table 9 which leads to increasing levels of GB exports, as will be shown in Section 4.3. 

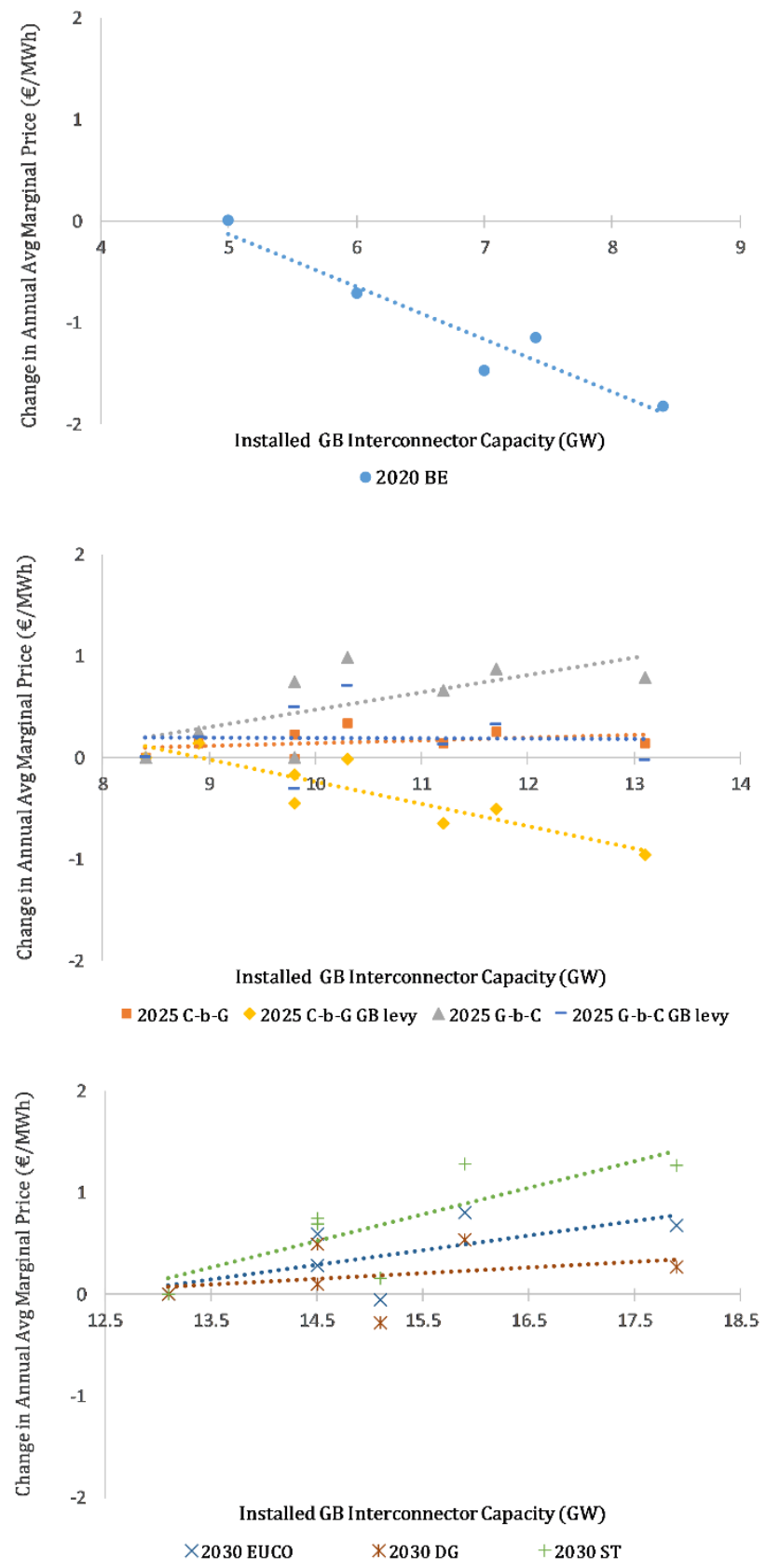

Figure 3 - Change in annual average GB marginal price under different interconnector and background scenarios 


\subsection{Interconnector Flow Analysis}

\subsubsection{Interconnector Utilisation}

The magnitude and direction of flows over interconnectors in the coming years is of crucial importance not just to their own business case but to their eventual impact on the markets they interconnect. Table 11 summarises aggregated GB interconnector flows for selected interconnection scenarios within each generation background and price scenario to give an overview of their impact. Combined interconnector utilisation is calculated as the sum of the absolute value of power transfers into or out of GB in each hour, divided by the total interconnector capacity. The value given is the average of that for a full year.

Table 11 - Summary of aggregated GB interconnector energy transfers for selected scenarios (TWh)

\begin{tabular}{|c|c|c|c|c|c|}
\hline $\begin{array}{c}\text { Background } \\
\text { scenario }\end{array}$ & $\begin{array}{c}\text { Interconnector } \\
\text { scenario }\end{array}$ & $\begin{array}{c}\text { Total } \\
\text { GB } \\
\text { import }\end{array}$ & $\begin{array}{c}\text { Total } \\
\text { GB } \\
\text { export }\end{array}$ & \begin{tabular}{|c|} 
Net GB \\
transfers \\
(import +ve) \\
\end{tabular} & $\begin{array}{c}\text { Combined } \\
\text { interconnector } \\
\text { utilisation } \\
\end{array}$ \\
\hline \multirow{2}{*}{$2020 \mathrm{BE}$} & S1 - 5.0 GW & 31.9 & 4.6 & 27.3 & $84 \%$ \\
\hline & S5 - 8.4 GW & 55.1 & 7.0 & 48.2 & $85 \%$ \\
\hline \multirow{2}{*}{2025 C-b-G } & S1 - 8.4 GW & 27.8 & 14.0 & 13.8 & $57 \%$ \\
\hline & S8 - 13.1 GW & 36.0 & 17.8 & 18.2 & $47 \%$ \\
\hline \multirow{2}{*}{$\begin{array}{c}2025 \text { C-b-G } \\
\text { GB levy }\end{array}$} & $\mathrm{S} 1-8.4 \mathrm{GW}$ & 44.5 & 10.4 & 34.1 & $75 \%$ \\
\hline & S8 - 13.1 GW & 61.7 & 13.9 & 47.7 & $66 \%$ \\
\hline \multirow{2}{*}{2025 G-b-C } & S1 - 8.4 GW & 15.3 & 25.0 & -9.7 & $55 \%$ \\
\hline & S8 - 13.1 GW & 20.4 & 31.8 & -11.3 & $46 \%$ \\
\hline \multirow{2}{*}{$\begin{array}{c}2025 \text { G-b-C } \\
\text { GB levy }\end{array}$} & S1 - 8.4 GW & 35.1 & 12.4 & 22.7 & $65 \%$ \\
\hline & S8-13.1 GW & 47.1 & 16.4 & 30.6 & $56 \%$ \\
\hline \multirow{2}{*}{2030 EUCO } & S1 - 13.1 GW & 24.5 & 42.3 & -17.8 & $58 \%$ \\
\hline & S6 - 17.9 GW & 30.9 & 52.7 & -21.8 & $53 \%$ \\
\hline \multirow{2}{*}{2030 DG } & S1 - 13.1 GW & 26.2 & 26.3 & -0.1 & $46 \%$ \\
\hline & S6 - 17.9 GW & 32.4 & 31.5 & 1.0 & $41 \%$ \\
\hline \multirow{2}{*}{$2030 \mathrm{ST}$} & S1 - 13.1 GW & 15.2 & 37.1 & -21.9 & $46 \%$ \\
\hline & S6 - 17.9 GW & 18.6 & 43.2 & -24.5 & $40 \%$ \\
\hline
\end{tabular}

Further, to give an insight into the transfers between GB and a selection of individual countries, Figure 4 a) - d) details the utilisation of interconnectors between GB and France, the Netherlands, Norway and Ireland respectively across a range of selected scenarios. It can be seen from Table 11 that, in the earlier years with relatively little interconnection capacity, far more energy in imported into GB than is exported from it and overall interconnector utilisation is high, i.e. the interconnectors spend a lot of the time at or close to full capacity in one direction or the other. In the 2020 scenario 1, with $5 \mathrm{GW}$ of interconnection, utilisation of the GB links is high at $84 \%$ and GB imports of 31.9 TWh represent around $9.7 \%$ of GB demand. This is a little more than the previous maximum figures seen in 2014 and 2015 of around $9 \%$ and a step up from the $6 \%$ seen in 2018 (all in years when there was $4 \mathrm{GW}$ of interconnector capacity) (Dutton, 2019).

In 2020, as evidenced in Figure 4, utilisation of links to France, Belgium, the Netherlands and Norway is dominated by GB imports and reduces as new interconnection is added, e.g. France from $96 \%$ to $94 \%$ and Netherlands from $86 \%$ to $79 \%$ between Scenarios 1 and 5. The existing Irish link's utilisation varies between $44 \%$ and $47 \%$ as other GB interconnectors are added and in contrast with all the other links, GB is a net exporter. However, links to other countries have relatively higher utilisation than the Irish link and account for a higher proportion of the total GB flows in scenario 5 than in scenario 1 which explains why the combined utilisation figure actually rises in this case.

In 2025, the highest combined utilisations for the cases with $8.4 \mathrm{GW}$ of interconnector capacity are associated with high energy imports in the two cases in which the GB carbon levy is in place but are never more than $75 \%$ showing lower utilisation than in 2020 for all scenarios. Without the GB levy, the gas before coal scenarios show GB to be a net exporter of energy in both the $8.4 \mathrm{GW}$ and $13.1 \mathrm{GW}$ interconnector cases. In this background scenario, GB's nuclear-renewables-gas merit order is on average cheaper than that on the continent 
of Europe that still features coal and lignite. Figure 4 b) highlights how for example the link to the Netherlands in particular is dominated by GB exports in this scenario in stark contrast to the present day situation. Combined utilisation in the $13.1 \mathrm{GW}$ interconnector case for this background scenario is low at $46 \%$. Utilisation is also low $(47 \%)$ in the coal before gas scenario with $13.1 \mathrm{GW}$ of interconnector capacity although, in this case, GB is a net importer of energy.

Removal of the GB specific levy and addition of new interconnectors both act to bring prices in GB and its neighbours close together. This results in an increasing number of hours in which the price differences between GB and its neighbours are insufficient to overcome the hurdle cost associated with interconnector power losses. An illustration of this phenomenon is given in Figure $5 \mathrm{a}$ ) and b) which compares the annual distribution of hourly price differences between the markets of GB and Belgium for two 2025 scenarios. This shows an increase in the number of hours in which the price difference between the two countries is close to zero with both the addition of new GB interconnector capacity and the removal of the GB specific carbon levy.

In 2030, the different scenarios show GB either as a significant exporter of energy or in balance with its neighbours, importing as much as it exports. In all cases, the utilisation of the total link capacity is relatively low ranging between $40 \%$ and $58 \%$. The background scenario in which GB's net transfer is nearly zero - 2030 DG - has around $26 \mathrm{TWh}$ each way in the $13.1 \mathrm{GW}$ interconnector case and $32 \mathrm{TWh}$ in the $17.9 \mathrm{GW}$ case. These figures may be compared with a total GB electrical energy demand in the 2030 DG scenario of $335 \mathrm{TWh}$. The 2030 EUCO scenario sees the highest level of interconnector utilisation of the three, largely driven by the scenario having a much larger build out of GB nuclear capacity than the others which in turn drives higher GB exports. In the 2030 ST scenario GB is among the cheapest market on average amongst its neighbours which results in lower GB imports and lowest overall utilisation.

The results show a broad shift of GB from a heavily importing market to either a more balanced picture or to a net exporting market in future years. This finding is comparable to that of recent analysis of different 2030 pathways by National Grid ESO in their Future Energy Scenarios publication (National Grid ESO, 2020) 


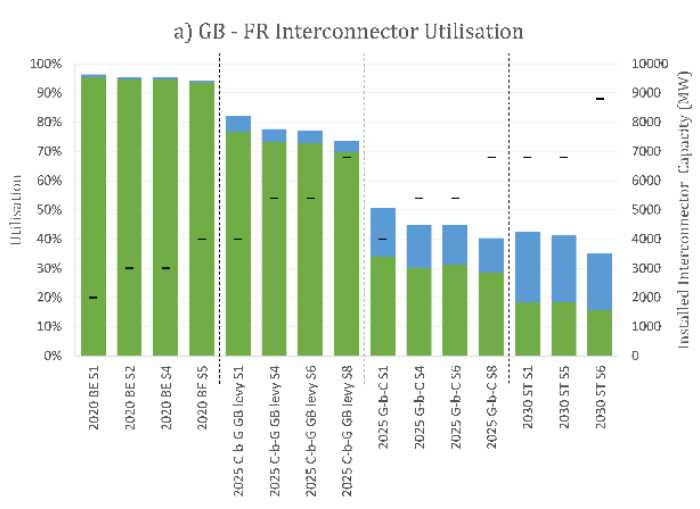

Selected background and interconnector scenarios

GB Imports = GB bxports - Interconnector Capacity

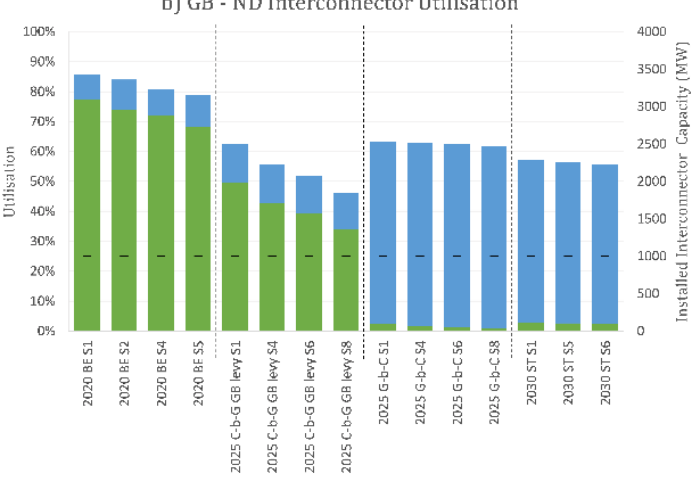

Selected background and interconnector scenarios

c) GB - NO Interconnector Utilisation

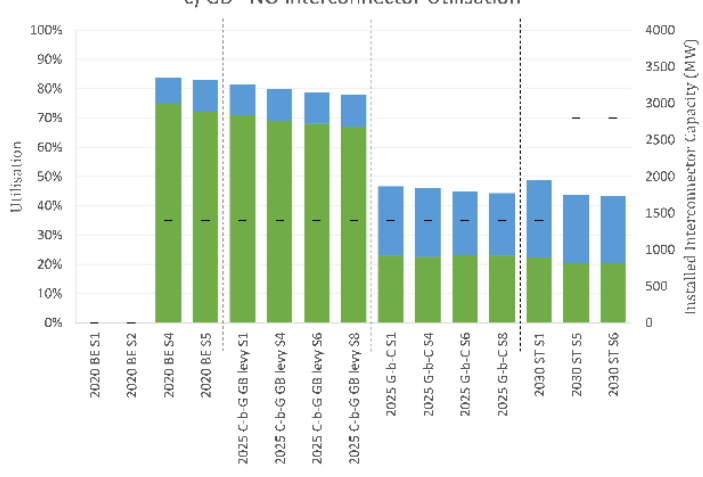

Selected background and interconnector scenarios

- GB Imports I GB Exports - Interconnector Capacity

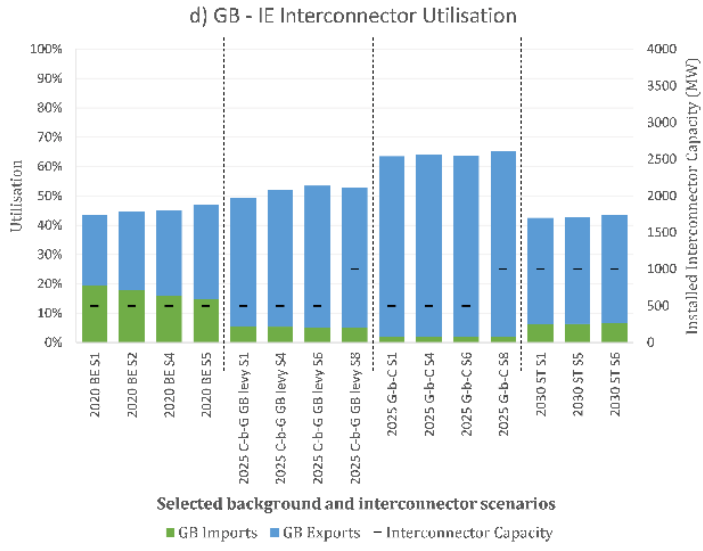

Figure 4 - Utilisation of interconnector capacity on links between GB and a) France, b) the Netherlands, c) Norway and d) Ireland 

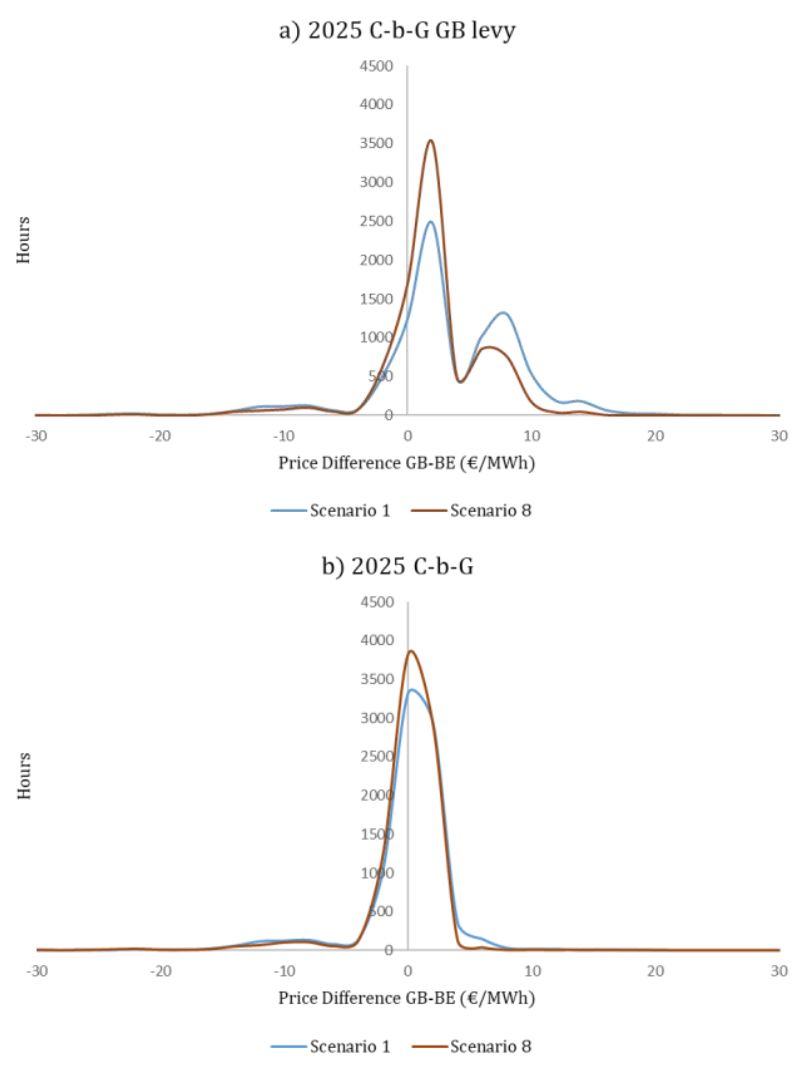

Figure 5 - Annual distribution of hourly market price difference between GB and Belgium for background scenario a) 2025 C-b-G GB levy and b) 2025 C-b-G (+ve => GB more expensive)

\subsubsection{Interconnector Revenues}

Reducing utilisation of interconnector capacity and converging market prices between GB and its neighbours both have a direct impact on the revenue potential that can be gained via congestion rent, calculated as the volume of interconnector flow multiplied by the price difference in the connecting markets for any given hour, for both new and existing interconnector projects. Figure 6 is given to illustrate the impact on congestion rent revenue by analysing the congestion per MW of installed interconnector capacity over a range of scenarios for the links between GB and France.

For 2020, the addition of two new interconnectors doubles the total installed capacity between GB and France from $2 \mathrm{GW}$ in scenario 1 to $4 \mathrm{GW}$ in scenario 5. Although the monetary value of congestion rent increases by around $47 \%$ between the two scenarios (from $€ 242 \mathrm{~m}$ to $€ 356 \mathrm{~m}$ ) this constitutes a $26 \%$ drop in annual revenue potential across the links on a per MW of installed capacity basis, from $€ 121 \mathrm{k} / \mathrm{MW}$ to $€ 89 \mathrm{k} / \mathrm{MW}$.

For 2025 Figure 6 illustrates another step change loss in revenue potential from the interconnectors associated with the changing background scenarios and convergent market prices between GB and its neighbours. For interconnector scenario 1, with $4 \mathrm{GW}$ installed capacity between GB and France and 8.4GW installed in total, the congestion rent potential across all the 2025 background scenarios ranges between $€ 32$ 60k/MW, significantly lower than scenario 5 in 2020 which has the same level of interconnection. It is also shown that additional interconnection capacity further erodes revenue potential. For example the addition of a further $2.8 \mathrm{GW}$ of interconnector capacity up to $6.8 \mathrm{GW}$ total reduces the congestion rent potential per MW in the $2025 \mathrm{C}-\mathrm{B}-\mathrm{G}$ GB levy scenario by a further $39 \%$ from $€ 59 \mathrm{k} / \mathrm{MW}$ in scenario 1 to $€ 36 \mathrm{k} / \mathrm{MW}$ in scenario 8. 


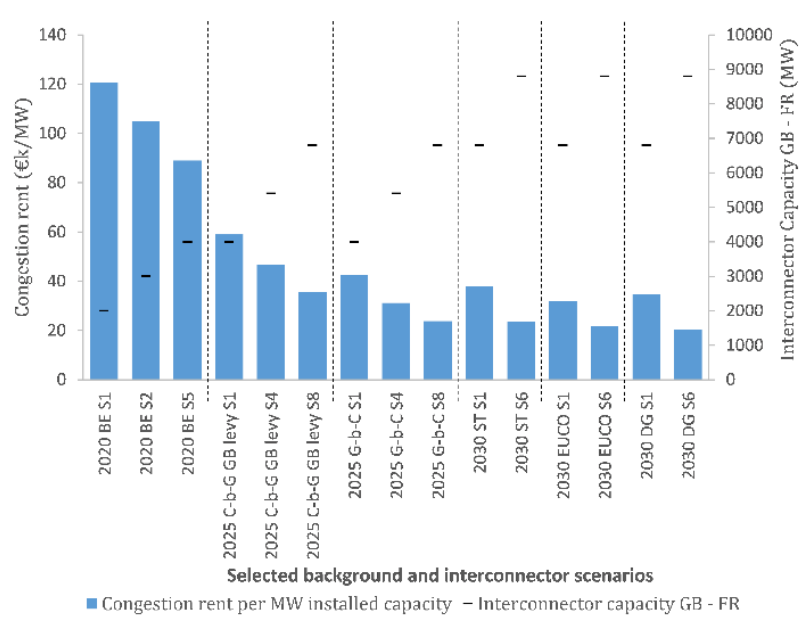

Figure 6 - Annual congestion rent per MW of installed capacity for interconnectors between GB and France for a selection of scenarios

This trend continues in the 2030 scenarios where congestion rent revenues drop from a range of $€ 32-38 \mathrm{k} / \mathrm{MW}$ with $6.8 \mathrm{GW}$ of interconnection between GB and France to between $€ 20-24 \mathrm{k} / \mathrm{MW}$ with $8.8 \mathrm{GW}$ of interconnection. This represents a five to six fold reduction in the per MW revenue potential for interconnections between GB and France compared with the representative today case.

The results provide evidence that new interconnectors can cannibalise the market opportunities of those that went before them and it should be noted that this phenomenon is also true for interconnectors to neighbouring countries. Figure $4 \mathrm{~b}$ ), for example, shows a large drop in the utilisation of the link between GB and Netherlands due to the addition of interconnectors between GB and other neighbouring markets. This has implications for the medium to long term viability of the merchant interconnector model if market based revenue potential is likely to be more scarce and in GB it also raises questions around the continued viability of the present cap \& floor regulatory regime for stimulating investment in new interconnector capacity. It should be noted that interconnectors may also look to supplement their income via balancing and ancillary service markets. Given the increasing need for flexibility to manage the evolving electricity system and the potential for more integrated balancing markets in future there is the potential to offset some of the challenging economics raised by this analysis. Indeed, interconnectors like BritNed do already derive a significant portion of their income via other revenue streams such as ancillary service markets (BritNed, 2020). 


\subsection{Carbon Emissions Analysis}

Increased interconnection to facilitate access to different generation resources may also be expected to affect carbon emissions associated with electricity production. Table 12 shows a comparison between GB and total European carbon emissions for selected interconnector scenarios in each of the eight generation and price backgrounds investigated.

Table 12 - Comparison of GB and total European carbon emissions across a range of background and interconnector scenarios $\left(\mathrm{MtCO}_{2} \mathrm{e}\right)$

\begin{tabular}{|c|c|c|c|c|c|c|c|}
\hline \multirow[t]{2}{*}{$\begin{array}{l}\text { Background } \\
\text { Scenario }\end{array}$} & \multirow[t]{2}{*}{$\begin{array}{c}\text { Interconnector } \\
\text { Scenario }\end{array}$} & \multicolumn{2}{|c|}{ Emissions } & \multicolumn{2}{|c|}{$\begin{array}{c}\text { Interconnector } \\
\text { scenario } \\
\text { impact }\end{array}$} & \multicolumn{2}{|c|}{$\begin{array}{c}\text { Emissions } \\
\text { change } \\
\text { relative to } \\
\text { baseline }\end{array}$} \\
\hline & & GB & Total & GB & Total & GB & Total \\
\hline \multirow{2}{*}{$2020 \mathrm{BE}$} & S1 - $5.0 \mathrm{GW}$ & 44.5 & 776.6 & - & - & - & - \\
\hline & S5 - 8.4 GW & 36.3 & 777.5 & -8.1 & 0.9 & -8.1 & 0.9 \\
\hline \multirow{2}{*}{2025 C-b-G } & S1 - 8.4 GW & 45.6 & 785.9 & - & - & 1.1 & 9.3 \\
\hline & S8 - 13.1 GW & 43.5 & 785.1 & -2.1 & -0.8 & -1.0 & 8.5 \\
\hline \multirow{2}{*}{$\begin{array}{l}2025 \text { C-b-G } \\
\text { GB levy }\end{array}$} & S1 - 8.4 GW & 35.8 & 786 & - & - & -8.7 & 9.5 \\
\hline & S8 - 13.1 GW & 30.7 & 786.3 & -5.1 & 0.3 & -13.8 & 9.8 \\
\hline \multirow{2}{*}{2025 G-b-C } & S1 - 8.4 GW & 51.8 & 591.2 & - & - & 7.3 & $\mid-185.4$ \\
\hline & S8 - 13.1 GW & 52.3 & 589.4 & 0.5 & -1.8 & 7.8 & -187.2 \\
\hline \multirow{2}{*}{$\begin{array}{l}2025 \text { G-b-C } \\
\text { GB levy }\end{array}$} & S1 - 8.4 GW & 39.9 & 596.9 & - & - & -4.6 & $\mid-179.7$ \\
\hline & S8 - 13.1 GW & 36.9 & 596.5 & -3 & -0.4 & -7.6 & $\mid-180.1$ \\
\hline \multirow{2}{*}{2030 EUCO } & S1 - 13.1 GW & 33.7 & 532 & - & - & -10.8 & -244.6 \\
\hline & S6 - 17.9 GW & 34.4 & 528.9 & 0.7 & -3.1 & -10.1 & -247.7 \\
\hline \multirow{2}{*}{2030 DG } & S1 - 13.1 GW & 39.7 & 643 & - & - & -4.8 & -133.6 \\
\hline & S6 - 17.9 GW & 39 & 641.6 & -0.7 & -1.4 & -5.5 & $\mid-135.0$ \\
\hline \multirow{2}{*}{$2030 \mathrm{ST}$} & S1 - 13.1 GW & 45.4 & 535.9 & - & - & 0.9 & $\mid-240.7$ \\
\hline & S6 - 17.9 GW & 46.1 & 533.9 & 0.7 & -2 & 1.6 & -242.7 \\
\hline
\end{tabular}

\subsubsection{Impact of merit order and background generation mix}

In 2020 we observe total emissions of around $777 \mathrm{MtCO}_{2} \mathrm{e}$. In the two 2025 coal before gas scenarios this level rises by around 8-9 $\mathrm{MtCO}_{2} \mathrm{e}$ with gains through increased renewable capacity offset by reductions in the nuclear fleet allowing greater market access to thermal plants. However, there is an almost $25 \%$ emissions reduction arising from an increased price of carbon which flips the merit order to the 2025 gas before coal scenarios. Similar reductions relative to 2020 can be observed when looking at the three ENTSO-E 2030 scenarios. The 2030 distributed generation scenario has a greater roll out of renewable energy than the 2030 sustainable transition scenario. However, the carbon price in the former means coal plants remain slightly cheaper than even the most efficient gas plants which leads to $20 \%$ higher emissions than in the sustainable transition scenario which has gas cheaper than coal in the merit order. The 2030 EUCO scenario is exceptional in that despite it having the lowest cost of carbon it also produces lowest total emissions overall which can largely be attributed to the assumption that significantly more nuclear power is retained or replaced in this scenario compared with the other two ENTSO-E 2030 scenarios.

\subsubsection{Impact of GB carbon price floor}

From Table 12 it can be seen that, in GB, in spite of the closure of coal plant, the 2025 background scenarios after cessation of the GB carbon levy have higher emissions than the 2020 scenario with same $8.4 \mathrm{GW}$ of interconnection. This can be explained by the closure of nuclear power stations and reduced imports and increased exports on interconnectors allowing increased access to market for polluting GB plant. If the carbon levy remains in place, GB emissions are between around 20-30\% lower than in the same generation background 
without the levy. However, when looking at Europe as a whole, we see that overall emissions are higher in those scenarios. The model shows that GB gas generation is out of merit in comparison with higher emitting fossil fuelled plant on the continent and that GB imports more energy (see Table 11). In effect, the levy has caused GB carbon emissions to be 'offshored' with a detrimental effect on total emissions. While the carbon price floor remains present it can be seen from Table 12 and Table 13 in Section 4.4.3 that additional interconnection acts to reduce emissions in GB. This will also reduce the tax revenues raised from this policy instrument. In the 2020 $\mathrm{BE}$ scenario GB emissions reduce by as much as $8.1 \mathrm{MtCO}_{2} \mathrm{e}$ with the addition of $3.4 \mathrm{GW}$ of new interconnection which translates to a loss of $€ 170 \mathrm{~m} / \mathrm{yr}$ in carbon tax revenue for the government.

\subsubsection{Country level impact of GB interconnection}

To help further explain the overall findings of Table 12, Table 13 gives the relative change in emissions for a range of selected countries as new interconnectors are added in the $2020 \mathrm{BE}$ background scenario.

Table 13 - Change in carbon emissions relative to interconnector Scenario 1 by country for $2020 \mathrm{BE}$ background scenario $\left(\mathrm{MtCO}_{2} \mathrm{e}\right)$

\begin{tabular}{|l|c|c|c|c|c|}
\hline Country & Scenario & Scenario & Scenario & Scenario & Scenario \\
\hline Belgium & 4.4 & 0.1 & 0.1 & 0.1 & 0.1 \\
\hline Czech R & 43.9 & 0.0 & 0.0 & 0.1 & 0.2 \\
\hline Germany & 200.5 & 0.6 & 1.1 & 2.7 & 3.1 \\
Denmark & 6.1 & 0.0 & 0.0 & 0.4 & 0.4 \\
\hline Spain & 62.5 & 0.4 & 0.9 & 0.5 & 1.0 \\
France & 10.2 & 0.8 & 1.6 & 0.8 & 1.6 \\
G. Britain & 44.5 & -2.6 & -5.1 & -5.9 & -8.1 \\
R. Ireland & 11.5 & -0.1 & -0.2 & -0.2 & -0.3 \\
Italy & 75.3 & 0.3 & 0.6 & 0.5 & 0.8 \\
N. Ireland & 1.5 & -0.1 & -0.1 & -0.1 & -0.2 \\
Netherlands & 33.8 & 0.0 & 0.0 & 0.4 & 0.4 \\
Norway & 0.1 & 0.0 & 0.0 & 0.0 & 0.0 \\
Poland & 106.6 & 0.1 & 0.1 & 0.6 & 0.6 \\
Rest Europe & 175.6 & 0.1 & 0.2 & 1.2 & 1.3 \\
\hline Total & 776.6 & -0.5 & -0.7 & 1.3 & 0.9 \\
\hline
\end{tabular}

It can be seen that, in 2020 between scenarios 1 and 5, the addition of new interconnectors reduces emissions in $\mathrm{GB}$ by more than $8 \mathrm{MtCO}_{2} \mathrm{e}$ with small reductions also seen in the two Irish markets. However, we actually observe a small net increase in emissions of $0.9 \mathrm{MtCO}_{2} \mathrm{e}$ for Europe as a whole with emissions reductions in GB being more than offset by the combined increase in emissions that the new interconnectors facilitate across the rest of the continent. The interconnectors are shown to not only enable greater emissions from countries to which GB is directly linked - Belgium, France and the Netherlands - but also to countries further afield, in particular Germany which has an abundance of relatively low cost coal and lignite plant.

A closer look at the results reveals that GB emissions are driven by large reductions in the utilisation of coal (1.2 TWh, 53\%) and gas (19.2 TWh, 19\%) plants between scenarios 1 and 5. As well affecting emissions, these falls affect the economic viability of less utilised plant. Gas utilisation across Europe as a whole reduces by 12.1 TWh. However, there are increases in the use of lignite $(0.8 \mathrm{TWh})$ and coal $(5.4 \mathrm{TWh})$ outside GB which lead to the slightly increased emissions level. This finding is similar to that of (Aurora Energy Research, 2016).

A point of note from Table 13 is that the impact of an interconnector depends on the countries it connects. We see that addition of an interconnector from GB to Norway (Scenarios 4 and 5) produces a net increase in emissions in large part due to the increased access to market they facilitate for German coal and lignite. In contrast, interconnectors to France produce a net reduction in emissions.

\subsubsection{Impact of interconnection on GB wind energy curtailment}

As previously mentioned, one of the perceived key benefits of new interconnection capacity is its ability to 
help facilitate the expansion of renewable generation capacity. To investigate the impact of GB interconnection capacity on utilisation of future wind energy capacity, studies are conducted using the 2030 ST background scenario. The level of GB interconnection is varied between the $5 \mathrm{GW}$ of capacity in operation in 2020 and the maximum capacity considered for 2030 of $17.9 \mathrm{GW}$. The $2030 \mathrm{ST}$ scenario contains a total wind capacity in $\mathrm{GB}$, onshore and offshore, of around $38.3 \mathrm{GW}$. This can be compared with the recently elected government who set a manifesto ambition for $40 \mathrm{GW}$ of offshore wind energy alone by 2030 . To reflect the fact that wind deployment in GB could be significantly greater than is considered in the baseline 2030 scenarios, an additional study is performed on a $2030 \mathrm{ST}$ background that assumes an offshore wind energy capacity in GB of $40 \mathrm{GW}$, increasing the total installed wind capacity to $56.1 \mathrm{GW}$. The results are given in Table 14, although it should be noted that they represent a minimum level of 'spilled' wind energy due to export constraints alone as the modelling does not account for additional network or system operation constraints within each country.

It is shown that increased interconnection has a significant bearing on the expected level of 'spilled' energy, i.e. that available from wind farms but where the level of demand plus export capacity in certain hours is insufficient to use it. In the scenario which considers $40 \mathrm{GW}$ of offshore wind in GB, installing a total of 12.9 GW of additional GB interconnection capacity facilitates the additional utilisation of 1 TWh of wind energy per year compared with a scenario where no new interconnectors are added in the next decade.

Table 14 - Annual spilled wind energy in GB due to export constraints for different 2030 background generation and interconnector scenarios

\begin{tabular}{|c|c|c|}
\hline \multirow{2}{*}{$\begin{array}{c}\text { GB interconnector } \\
\text { Capacity }\end{array}$} & \multicolumn{2}{|c|}{ Annual Spilled Wind Energy (GWh) } \\
\hline & $\begin{array}{l}2030 \text { ST with } 38.3 \\
\text { GW of wind in GB }\end{array}$ & $\begin{array}{c}2030 \text { ST with } 56.1 \\
\text { GW wind in GB }\end{array}$ \\
\hline 5 GW & 360.1 & 1344.3 \\
\hline 8.4 GW & 163.9 & 975.8 \\
\hline $13.1 \mathrm{GW}$ & 53.9 & 587.8 \\
\hline $17.9 \mathrm{GW}$ & 10.7 & 343.8 \\
\hline
\end{tabular}

\section{$5 \quad$ Policy Implications and Conclusion}

There are several policy implications that follow from the analysis of new GB interconnector roll out and potential future generation background pathways reported in this paper. It shows that, in the near term, increased interconnection is likely to be beneficial for GB both in terms of reduced emissions at a national level and reduced average electricity prices for GB consumers. As GB becomes increasingly coupled with the European market via further interconnection and the penetration of low marginal cost renewables increases, the difference between wholesale prices in the GB market and those in neighbouring countries changes significantly. This means that in many 2025 and 2030 scenarios GB has transitioned from a high net importer over its interconnectors to a net exporter, often of surplus renewable energy. In these scenarios it can be observed that additional interconnection can increase prices for the GB consumer on average, especially where the GB carbon price floor is removed and carbon prices are levelised across the continent. This has implications for the manner in which the GB regulator assesses the case for interconnector projects on a GB consumer welfare basis.

Another key finding concerns the existing GB specific carbon price floor policy. Despite being a strong signal for decarbonisation of the GB electricity system, our results suggest that may actually lead to increased overall emissions. The policy makes more heavy polluting coal and lignite stations in the rest of Europe cheaper than coal and gas in GB. It also seems clear that the policy is at least in part behind the finding that additional GB interconnection capacity in the 2020 background scenario would also lead to an overall increase in European emissions.

The expected removal of the GB carbon levy in the coming years will act to levelise carbon costs across the continent (assuming the UK either remains a party to or closely mirrors the carbon prices set by the EU-ETS) and therefore to reduce GB wholesale market prices on average. The growth of low marginal cost renewable energy will add to this effect and it can be expected that in some 2025 pathways and most 2030 pathways GB will have transitioned into a predominantly exporting market. 
At present the carbon price floor and the addition of new interconnection projects act to heavily reduce market access for GB thermal stations. This drives down emissions but also affects the economics of such generators to the extent that some may be unviable in the near term without additional income from the capacity market or ancillary services. Furthermore, these stations compete with interconnectors in the capacity market and face some costs that interconnectors do not, in particular the requirement to pay transmission network use of system charges (Dept. for Business Energy and Indutrial Strategy, 2019). However, the removal of the carbon price floor and GB's expected medium term transition to being an export market could lead to renewed and increased market access opportunities for the very same plant. Until flexible, schedulable generation plant fuelled from low carbon sources becomes available or interconnection capacity is massively increased, the intermittency of renewables means that a certain amount of flexible gas plant will still be required in GB. The most cost-effective way of meeting this need is an important consideration for policy makers.

At the time of writing the United Kingdom has formally left the European Union but is in a transition period extending to the end of 2020. The government and devolved administrations have set out an intention to create a new UK emissions trading scheme (UK-ETS) to replace direct involvement in the EU-ETS. The proposal leaves open the option for this to be linked to the EU-ETS scheme or standalone and proposes a price floor of $£ 15 / \mathrm{MWh}$ within the scheme to replace the existing carbon price floor (UK Government and Devolved Administrations, 2020). Given this, it seems likely that GB carbon prices could be much more closely aligned to the EU-ETS price going forward. However, significant fluctuations in the EU-ETS price, including a sustained drop in price owing to reduced demand under current Europe wide restrictions on economic and social activity, in light of the onset of the Covid-19 pandemic, could affect this balance going forward. The results have shown that total emission reductions are best addressed by a continent wide effort to phase out polluting plant and price in carbon externalities while also increasing the penetration of low carbon generation sources. Unless balanced by appropriate policies elsewhere in Europe, localised emissions reductions obtained through schemes like the GB carbon price floor may be offset in the near term by increased emissions elsewhere on the continent given the presence of a highly interconnected European electricity market.

The long term viability of new and existing interconnector developments is also explored in the analysis. A significant number of new GB interconnectors are currently under construction or in development. Commissioning of all of them plus expected changes to GB's generation mix will significantly change the dynamics of the GB electricity market's interactions with the rest of Europe. GB transitions from a large net importer from all but the Irish market to a situation where it is a relatively cheap market amongst its neighbours and predominantly exports to countries like Belgium and the Netherlands. Exports to other low cost markets like France and Norway also increase with a much more balanced level of imports and exports. The combined overall utilisation of all links is expected to drop from around $85 \%$ in the 2020 scenarios assessed here to between $46-75 \%$ in the 2025 scenarios and between $40-58 \%$ in the 2030 scenarios. The results have also shown that convergent market prices between GB and its neighbours and the reduced utilisation of interconnectors as more capacity is built results in a cannibalisation of market opportunity and suggests a significant reduction in the revenue potential for individual interconnector projects compared with what they could expect to generate under present day conditions. For interconnectors to France the results suggest at least a fivefold reduction in congestion rent revenue potential per MW of installed interconnector capacity in 2030 scenarios compared with the today case. This and the UK's exit from the European Union, which may make regulatory approvals more difficult and change the way that revenues are collected, may result in some of the planned interconnectors not being taken forward. This would not only reduce the extent to which interconnector imports can contribute to meeting GB demand during periods of low output from domestic renewables but would also increase 'spillage' of GB wind power in high wind hours. A re-evaluation of the way in which interconnector investments are incentivised and remunerated may then be required to continue to harness their benefits while incorporating ever increasing volumes of variable renewables.

It should be noted that, since publication of the 2018 TYNDP, various national and EU climate targets, notably the National Energy and Climate Plans (NECPs), have been updated. Many of these have been taken into account by ENTSO-E and ENTSOG in the 2020 TYNDP published in June 2020. For example a comparison of the "National Trends" scenario for 2030 from the 2020 TYNDP with the 2030 ST scenario from the 2018 TYNDP used in this work shows, for the equivalent nodes, an $18 \%$ increase in total offshore wind 
capacity, a $27 \%$ increase in onshore wind capacity and a $25 \%$ reduction in coal and lignite capacity. The scenarios developed for the 2020 TYNDP do not account for major policy developments in the UK announced in December 2020, notably the UK's commitment to a 2030 Nationally Determined Contribution and the target for $40 \mathrm{GW}$ offshore wind capacity in British waters by 2030 (UK Government, 2020). The differences highlighted are significant but not so fundamental as to alter the main conclusions from this study which focuses on the impact of new interconnection capacity. Nevertheless, future work by the authors will involve updating the model used in the current paper to take account of these updated perspectives alongside possible energy system pathways published by, in particular, National Grid ESO (National Grid ESO, 2020) and the UK's Climate Change Committee (Climate Change Committee, 2020).

\section{Acknowledgements}

The foundations for the work reported in this paper were laid as part of the research programme of the UK Energy Research Centre (EP/L024756/1). The final stages of work were part of a project on "The value of Interconnection in a Changing EU Electricity system (ICE)" (EP/R021333/1). Input from members of the industry advisory group in the ICE project is gratefully acknowledged. The data underpinning this publication are openly available from the University of Strathclyde KnowledgeBase at https://doi.org/10.15129/a3c61b7ade66-4599-980b-533df49435d5

\section{References}

Agora Energiewende and Sandbag, 2019. The European Power Sector in 2019. Up-to-date analysis on the electricity transition, [Online] - https://www.agora-energiewende.de/en/publications/the-european-power-sector-in-2019/.

Aurora Energy Research, 2016. Dash for Interconnection: The Impact of Interconnectors of the GB Market.

Baringa, 2014. New electricity interconnection to GB - operation and revenues.

Bell, K., Staffell, I., 2016. Audit of the BID3 Pan European Market Model for National Grid, [Online] https://pureportal.strath.ac.uk/en/publications/audit-of-the-bid3-pan-european-market-model-for-national-grid.

BritNed, 2020. Annual Accounts, https://www.britned.com/participants-portal/key-links-and-documents/annualaccounts/.

Climate Change Committee, 2020. Sixth Carbon Budget, [Online] - https://www.theccc.org.uk/publication/sixth-carbonbudget/.

Cludius, J., Hermann, H., Matthes, F.C., Graichen, V., 2014. The merit order effect of wind and photovoltaic electricity generation in Germany 2008-2016: Estimation and distributional implications. Energy Economics 44, 302-313.

Deane, J.P., Driscoll, Á., Gallachóir, B.P.Ó., 2015. Quantifying the impacts of national renewable electricity ambitions using a North-West European electricity market model. Renewable Energy 80, 604-609.

Dept. for Business Energy and Indutrial Strategy, 2019. Capacity Market: Five-year Review, [Online] https://www.gov.uk/government/publications/capacity-market-5-year-review-2014-to-2019.

Dutton, J., 2016. The politics of cross-border electricity market interconnection: the UK, Ireland and Greenlink UKERC, London

Dutton, J., 2019. UK-EU Electricity Interconnection: The UK's Low Carbon Future and Regional Cooperation After Brexit, in: Paper, E.G.B. (Ed.). E3G briefing paper, .

ENTSO-E, $2018 \mathrm{a}$ TYNDP $2018 \quad$ Scenario $\quad$ Report, [Online] https://docstore.entsoe.eu/Documents/TYNDP\%20documents/TYNDP2018/Scenario_Report_2018_Final.pdf.

ENTSO-E, 2018b. TYNDP 2018: Joint Scenarios Data - Input Data, [Online] - https:/tyndp.entsoe.eu/maps-data/.

ENTSO-E, 2018c. TYNDP 2018: Joint Scenarios Data - Load Series, [Online] - https:/tyndp.entsoe.eu/maps-data/.

ENTSO-E, 2020. Transparency Platform, [Online] - https://transparency.entsoe.eu/.

EurObserv'ER, 2019. The State of Renewable Energies in Europe, Edition 2018. 
European Comission, 2014a. European Energy Security Strategy, [Online] - http://eur-lex.europa.eu/legalcontent/EN/TXT/PDF/?uri=CELEX:52014DC0330\&from=EN.

European Comission, 2014b. A policy framework for climate and energy in the period from 2020 to 2030, [Online] https://eur-lex.europa.eu/legal-content/EN/TXT/?uri=CELEX:52014DC0015.

European Commision, 2020. Market analysis: Gas and electricity market reports.

European Parliament, 2009. Regulation (EC) No 714/2009 of the European pariliament and of the council: on conditions for access to the network for cross-border exchanges in electricity and repealing Regulation (EC) No 1228/2003.

Geske, J., Green, R., Staffell, I., 2020. Elecxit: The cost of bilaterally uncoupling British-EU electricity trade. Energy Economics 85, 104599.

Hirth, L., 2018. What caused the drop in European electricity prices? A factor decomposition analysis. The Energy Journal, International Association for Energy Economics 0.

HM Government, 2019. Industrial Strategy Offshore Wind Sector Deal. BEIS, Avalaible online: https://www.gov.uk/government/publications/offshore-wind-sector-deal.

Houghton, T., Bell, K., Doquet, M., 2012. The economic case for developing HVDC-based networks to maximise renewable energy utilisation across Europe: an advanced stochastic approach to determining the costs and benefits, Paper presented at Cigre 2012, Paris.

Hurst, D., 2018. Carbon Price Floor (CPF) and the price support mechanism, House of Commons Library.

Investing.com, 2020. https://uk.investing.com/commodities.

M Doquet, C Fourment, Roudergues, J.M., 2011. Generation \& Transmission Adequacy of Large Interconnected Power Systems: A contribution to the renewal of Monte-Carlo approaches, IEEE Powertech 2011, Trondheim.

National Grid ESO, 2020. Future Energy Scenarios, [Online] https://www.nationalgrideso.com/document/173821/download.

National Grid Interconnectors, 2018. Connecting for a smarter future, [Onilne] https://www.nationalgrid.com/document/118641/download.

Newbery, D., 2016. A simple introduction to the economics of storage: shifting demand and supply over time and space. EPRG working paper 1626, Cambridge working paper in economics 1661.

Newbery, D., Gissey, G.C., Guo, B., Dodds, P.E., 2019. The private and social value of British electrical interconnectors. Energy Policy 133, 110896.

ofgem, 2013. Cap and Floor Regime for Regulated Electricity Interconnector Investment for application to project NEMO.

Redpoint Energy Limited, 2013. Impacts of further electricity interconnection on Great Britain.

RTE, 2019a. Anatares_Simulator 7.0.1: Optimization Problems Formulation.

RTE, 2019b. Antares_Simulator 7.0.1: General Reference Guide.

Staffell, I., Pfenninger, S., 2016. Using bias-corrected reanalysis to simulate current and future wind power output. Energy $114,1224-1239$.

Turvey, R., 2006. Interconnector economics. Energy Policy 34, 1457-1472.

UK Government, 2020. New plans to make UK world leader in green energy, [Online] https://www.gov.uk/government/news/new-plans-to-make-uk-world-leader-in-green-energy.

UK Government and Devolved Administrations, 2020. The future of UK carbon pricing, Available online: https://www.gov.uk/government/consultations/the-future-of-uk-carbon-pricing.

Ward, K.R., Green, R., Staffell, I., 2019. Getting prices right in structural electricity market models. Energy Policy 129, 1190-1206. 